\title{
ETCS ermöglicht Energieeinsparungen im Bahnbetrieb ${ }^{1}$
}

\author{
J. Braun
}

Das europäische Zugsicherungssystem ETCS und sein Funk-Subsystem GSM-Rail, beide Teil des europäischen ERTMS-Standardisierungsprogramms, sind im Allgemeinen für ihre Rolle bekannt, die sie bei der Sicherheit des grenzüberschreitenden Eisenbahnverkehrs und der Kapazitätssteigerung spielen. Viel weniger bekannt ist die Tatsache, dass ERTMS auch eine entscheidende Rolle bei einem viel effizienteren Zugverkehr und einer viel effizienteren Steuerung der Eisenbahnverkehrsströme spielen kann. Dies führt nicht nur zu zusätzlichen Leistungsverbesserungen, sondern auch zu einer beträchtlichen Senkung des Energiebedarfs.

Die Senkung des Energiebedarfs basiert auf zwei Hauptfaktoren: Der erste Faktor besteht in einer erheblichen Minderung von Verkehrsbelastungen in intensiv genutzten Netzbereichen, der zweite Faktor in der Fähigkeit, die Antriebsenergie jedes einzelnen Zuges auf effizienteste Weise zu steuern. In beiden Fällen wird unnötiges Bremsen und Wiederbeschleunigen so weit wie möglich vermieden. Aufgrund der großen Menge an Zügen hat dies eine beträchtliche Auswirkung auf die Pünktlichkeit und den Energiebedarf.
Aufgrund der steigenden Energiekosten, der zunehmenden Sensibilisierung der Öffentlichkeit für Umweltfragen und der wachsenden Forderungen des Marktes nach Servicequalität handelt es sich bei diesem Aspekt von ERTMS um eine aufkommende Entwicklung im Eisenbahnsektor. Diese Präsentation gibt einen Eindruck der Rolle, die ERTMS bei der Verbesserung der dynamischen Eisenbahnprozesssteuerung spielen kann, zeigt die potentiellen Energieeinsparungen, die erzielt werden können, gibt eine Übersicht über die bereits entwickelten Anwendungen, nennt einige Anwendungsbeispiele und die erzielten Energieeinsparungen und entwirft nicht zuletzt eine klare Vision für die nahe Zukunft, wie die ERTMS-standardisierte Prozesssteuerung die Eisenbahnen noch "grüner" machen wird als sie bereits sind (Abb. 1)

\section{Abkürzungen}

ETCS: European Train Control System

ERTMS: European Rail Traffic Management System GSM-R: Global System for Mobile Communications - Rail(way)

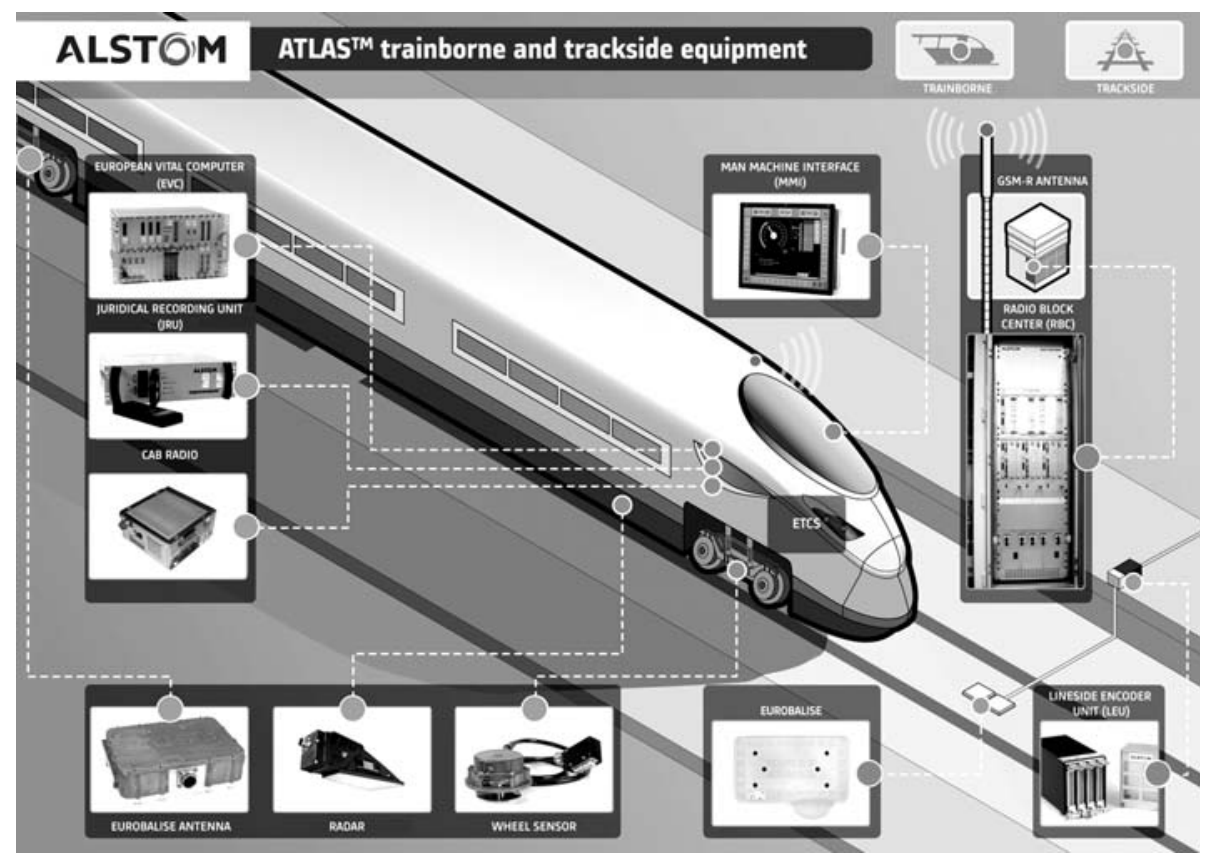

Abb. 1. ATLAS ${ }^{\mathrm{TM}}$ von Alstom

Kurzfassung eines Vortrags der 49. Fachtagung der Österreichischen Gesellschaft für Energietechnik (OGE) im OVE, die am 20. und 21. Oktober 2011 in Innsbruck stattfindet.

Braun, Johannes, Dipl.-Ing. (FH), Alstom Austria GmbH, Managing Director Transport, Clemens-Holzmeister-Straße 4, 1109 Wien, Österreich (E-Mail: johannes.braun@transport.alstom.com) 